\section{INVESTIGATIONS ON THE ESTIMATION OF INORGANIC PHOSPHORUS IN ANIMAL TISSUES.}

By A. C. Whittier.

Various methods and modifications for the extraction and the determination of inorganic and organic forms of phosphorus in animal tissues have been published, but there seems yet to be a lack of agreement in the work of the different investigators. A sharp separation of organic from inorganic phosphorus in the tissues, in the proportions present at the time of death, is rendered very difficult, owing to the chemical changes taking place in the tissues themselves as well as changes induced by agents employed in the estimation of these compounds.

In I 905 Emmet and Grindley published a method for the determination of inorganic phosphorus in cold water extracts of flesh. The essentials of their method were ( $I$ ) the condensation of a measured portion by heat, (2) the removal of the resulting coagula by filtration, (3) the precipitation of the inorganic phosphates with neutral ammonium molybdate after adding a minimum amount of nitric acid, (4) the reprecipitation of the dissolved precipitate by acid ammonium molybdate. The determination was completed in the regular gravimetric way for phosphorus.

Almost simultaneously Siegfried and Singewald published work done on flesh extracts. They recommended a method for the separation of inorganic and organic phosphorus consisting of a preliminary precipitation of the inorganic phosphates with barium chloride and ammonia; after precipitation was complete, the barium phosphate was filtered out. Organic phosphorus was determined on an aliquot of the filtrate and inorganic phosphorus obtained by difference.

Early in rg ro Forbes, et al., ${ }^{3}$ published a method for the extraction and determination of inorganic phosphorus applicable to muscle, liver, kidney and brain.

The extraction was accomplished by boiling the sample in ammonium sulphate solution, followed by repeated extractions with hot water. The determination was made by precipitating the inorganic phosphates with magnesia mixture and ammonia followed by the regular gravimetric method for phosphorus on the dissolved magnesium precipitate.

This method gave almost identical results with and without the application of heat to cold water extracts of flesh and agreed with results obtained by the Emmet and Grindley method.

Using the Siegfried and Singewald method, Stanley and Trowbridge's ${ }^{4}$ results showed that any method involving the use of heat previous to the separation of the organic and inorganic forms of phosphorus would give too high a figure for inorganic phosphorus in flesh extracts.

Working on beef loaf, these authors found only a trace of organic phosphorus after coagulating the extract by boiling.

\footnotetext{
1 J. Am. Chem. Soc., 28, 25.

2 Z. Nahr. Genussm., 9, 521

3 Bull. 215, 481, Ohio Agr. Exp. Sta,

4 ThIs JOURNAL, 2, 212 .
}

Emmet and Grindley made determinations on cooked and uncooked samples of flesh, but their results show no such wide variations for organic phosphorus as do the results of Stanley and Trowbridge which they obtained with and without the application of heat.

With such a diversity of results by different workers it seems desirable to collect additional data on this question. Our first work in this study was to compare the method used by Stanley and Trowbridge with the magnesia method used in this laboratory, employing magnesia mixture as a preliminary precipitating reagent.

An attempt to estimate the inorganic phosphorus directly on the washed barium phosphate precipitate was abandoned because of the white precipitate washing through the filter paper, more especially in the case of extracts of raw meat. This made it necessary to make the determination of the soluble organic phosphorus on an aliquot of the unwashed filtrate from the barium precipitation of inorganic phosphates. In order to obtain the inorganic phosphorus figure, it is then necessary to make determinations of the total soluble phosphorus and by difference calculate the inorganic phosphorus content.

TABLe I.-Comparison of the Barium and Magnesium Methods on Coagulated and Uncoagulated Flesh Extracts.

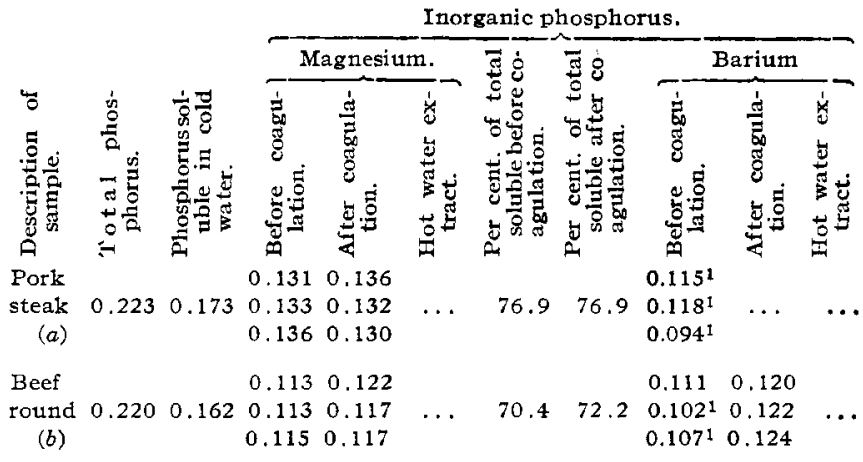

$\begin{array}{lllllll}\text { Beef } & 0.098 & 0.106 & 0.108 & 0.059^{1} & 0.109 & 0.114\end{array}$

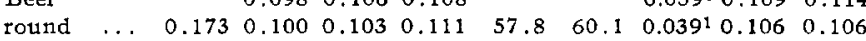

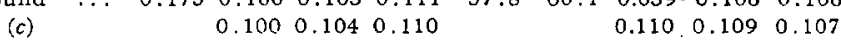

Fairly concordant results were obtained by the barium method, provided that the extract was first coagulated by boiling, or that the filtrate from the uncoagulated extract could be obtained perfectly clear on filtering off the barium phosphate precipitate.

This is in accord with the findings of Siegfried and Singewald who say, "Von den Filtraten, welch absolut klar sein mussen............."

Stanley and Trowbridge say: "The samples from the raw meats gave very little precipitate and the filtrates were in every case slightly cloudy."

Doubled No. $5^{89}$ blue ribbon filter papers were used, but with uncoagulated extracts the filtrates from the barium phosphate precipitation were cloudy. In two instances, however, as noted in the preceding table, clear filtrates were obtained by repeated filtering and the results on these clear filtrates give very nearly identical figures with those obtained by the same method on boiled extracts of the same sample. These

1. Filtrates from barium precipitation cloudy, 
two results are also in close agreement with determinations on both boiled and unboiled extracts of the same sample by the magnesium method.

Briefly stated, the objections to the barium method for inorganic or organic phosphorus determinations on flesh extracts, especially cold water extracts of raw meats, are:

(I) The probable retarding action of the proteids contained in a cold water extract on the precipitation of the inorganic phosphates by barium chloride and ammonia.

(2) The possibility that the organic material precipitated along with the barium phosphate contains organic phosphorus.

(3) The difficulty encountered in filtering off the barium phosphate precipitate. A cloudy filtrate from the barium phosphate precipitation gives a high figure for organic phosphorus.

(4) Its mechanical imperfections and length make it objectionable for a routine method.

After using barium chloride and ammonia in comparison with magnesia mixture as a preliminary precipitant of inorganic phosphorus, the writer concluded that magnesia was by far the better reagent to use in the further comparison of heated and unheated extracts of tissues, the chief reasons being:

(I) Less organic matter was thrown down with magnesium than with barium.

(2) The precipitate settled quickly.

(3) Filtration was rapid and gave a clear filtrate.

(4) The direct determination of inorganic phosphorus on the washed precipitate, with magnesia mixture as a precipitant, is much briefer than the indirect method by the use of barium chloride and ammonia.

Great difficulty was experienced in getting enough clear cold water extracts of liver, kidney and brain to make comparisons of coagulated and uncoagulated extracts. This was finally accomplished on samples $D, E, F$, and $G$ by the use of a Berkefeld filter.

Approximately 80 grams of finely ground sample was weighed out into a large beaker. A small amount of distilled water was added and the contents beaten up thoroughly with a stirring rod. The sample was then transferred to a graduated liter flask by the use of about $500 \mathrm{cc}$. of distilled water. This was shaken for about 30 minutes and then filled to the mark, poured into a large flask and made up to four liters. After shaking every five minutes for one hour the contents were allowed to settle and the supernatant liquid was poured into a Berkefeld filter. This gave a clear extract, but in the case of the brain it came through very slowly.

These samples were purchased from the local butchers and were at least two or three days' old.

In order to learn whether or not organic phosphorus changes to the inorganic state to any appreciable extent before determinations could be made on a routine scale after the death of an animal, a young pig was killed and the estimations on the different tissues were started immediately. Samples of the blood were caught in weighed bottles, the entire contents of each bottle being used for a determination. This insured a representative sample. The other tissues were immediately removed from the carcass, ground, sampled and weighed out in the least possible timè.

Cold extracts were made only on the muscle (H) of the ham, while the regular method as outlined in our previous article ${ }^{x}$ was employed on all the tissues named, including the sample of muscle for the sake of further comparison. The sample of muscle $(H)$ was kept on ice for 24 hours and the determination repeated in the same way as on the first day.

TABle II.-COMParison of COAgulated AND UNCOAgulated Extracts of animal Tissues, Using the Magnesium Method.

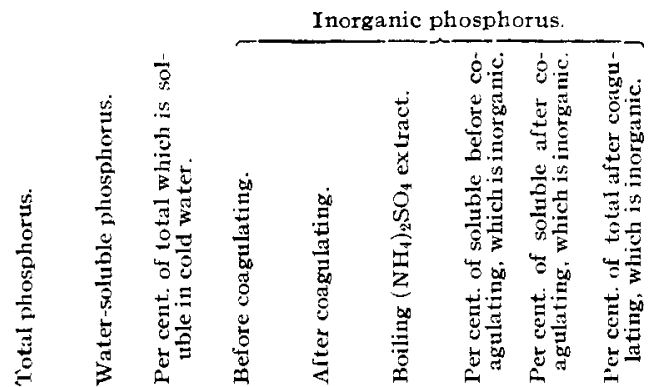

Pig muscle

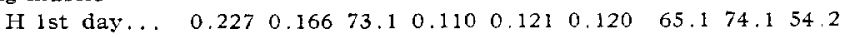
Pig muscle

$\begin{array}{lllllllllllll}H & \text { nd day } \ldots & 0.227 & 0.168 & 74.0 & 0.130 & 0.137 & 0.130 & 77.4 & 81.5 & 60.4\end{array}$

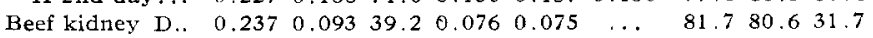
$\begin{array}{llllllllll}\text { Beef kidney } E_{1} . & 0.238 & 0.102 & 42.9 & 0.071 & 0.076 & \ldots & 69.6 & 74.5 & 31.9\end{array}$ $\begin{array}{lllllllllllll}\text { Beef liver F... } & 0.367 & 0.136 & 37.1 & 0.098 & 0.099 & \ldots & 72.1 & 72.8 & 27.0\end{array}$ $\begin{array}{lllllllllllll}\text { Calf brain G... } & 0.296 & 0.078 & 26.4 & 0.055 & 0.053 & 0.060 & 70.5 & 68.0 & 17.9\end{array}$

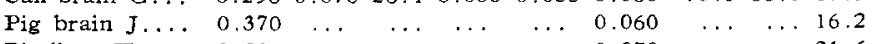

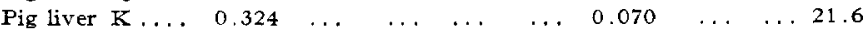
Pig blood L...

In the majority of cases the preceding table shows that where heat is applied a slight increase in per cent. of inorganic phosphorus occurs. The differences are small where they exist at all and in the writer's opinion are due, not to a change of organic to inorganic phosphorus, but to a better precipitation of the inorganic phosphates from the clearer solutions produced by coagulation.

The cold water extract of sample (H) (first day) gave a considerably lower figure for inorganic phosphorus than did the same extract on coagulation. This was possibly due to the larger amount of organic matter in this extract than is usually present, as this extract was prepared from the sample before rigor mortis had set in and was slightly milky in appearance. It is believed this condition prevented complete precipitation with magnesium mixture. It should be noticed, however, that the coagulated cold-water extract gave identical results with the hot ammoniumsulphate-extract.

If there is a progressive splitting up of the organic compounds of phosphorus by heat, one would expect a much higher figure for inorganic phosphorus from an extract procured by boiling the whole sample than from a cold-water extract which is simply coagulated by boiling. This is not the case, however, since hotwater extracts gave the same figure as did the coagu-

\footnotetext{
1 Bull, 215, 487, Ohio Agr. Exp. Sta.
} 
lated cold-water extracts. Sample H, on the second day, gave somewhat higher results for inorganic phosphorus than on the first day immediately after the death of the anima1. This was probably due to enzyme or bacterial action, or to both.

The cold-water extract from sample $b$, Table I, contained $0.1 \mathrm{Ig}$ per cent. inorganic phosphorus after coagulation. This extract after boiling for 2 hours with 0.2 per cent. $\mathrm{HCl}$ gave $0 . \mathrm{I} 2 \mathrm{I}$ per cent. of inorganic phosphorus, but determinations made after the extract had stood 36 hours in the laboratory gave a result of 0.14 I per cent. inorganic phosphorus. Either enzymes or bacteria, or both, increased the inorganic phosphorus one-sixth of the original amount, while boiling with acid made no appreciable difference.

This is in accord with results obtained by Siegfried and singewald.

\section{CONCLUSIONS.}

Stanley and Trowbridge's determinations of organic phosphorus by the barium method are too high on uncoagulated extracts on account of barium phosphate passing through the filter.

The temperature of boiling water has very little hydrolyzing action on the organic compounds of phosphorus in animal tissues.

Enzymes and bacteria seem to exert more of a hydrolyzing influence on organic phosphorus compounds of animal tissues than does boiling.

Coagulation of the proteids by boiling the extracts of tissues serves two purposes: (I) it clears the solution-a more complete precipitation resulting; (2) it arrests the action of enzymes and bacteria.

\section{ACKNOWLEDGMENTS.}

The author wishes to express his gratitude to Dr. E. B. Forbes for making this work possible and for assistance and suggestions rendered during this study. DEPARTMENT OF NUTRITION

OHIO AGR. EXPT. STATION. WOOSTER, OHIO.

\section{A VOLUMETRIC METHOD FOR ANTIMONY IN ALLOYS.} By George S. Jamieson.

The object of this paper is to describe an application of L. W. Andrews' iodate methodx to the determination of antimony in alloys, particularly "hard leads" and solders. The method is satisfactory because it is not interfered with by copper and iron, metals which frequently occur in small quantities in these alloys, and because it is rapid and accurate.

Two other iodimetric methods have been compared with this by the writer with less satisfactory results. The first, which is based upon getting the antimony into the pentavalent form in dilute hydrochloric acid solution, adding potassium iodide and titrating with sodium thiosulphate, gave good results in the absence of copper and iron, but was unsatisfactory in the presence of these metals. The other method, depending upon getting the antimony into the trivalent state in a sodium bicarbonate solution and 1 J. Am. Chem. Soc., 25, 756 (1903). titrating with iodine was found to give poor results, particularly with alloys containing much lead, as even when tartaric acid is used, the lead carbonate precipitate appears to hold antimony, thus causing low results.

Andrews showed that his iodate method was satisfactory for antimony by applying it to pure tartar emetic. The method has been further tested by the writer by dissolving weighed quantities of Kahlbaum's pure antimony in concentrated sulphuric acid and titrating it as described beyond. It is to be observed that this titration is carried out in the presence of I $^{-20}$ per cent. of actual hydrochloric acid, which gives iodine monochloride as the endproduct, according to the equation $2 \mathrm{SbCl}_{3}+\mathrm{KIO}_{3}+$ $6 \mathrm{HCl}={ }_{2} \mathrm{SbCl}_{5}+\mathrm{KCl}+\mathrm{ICl}+{ }_{3} \mathrm{H}_{2} \mathrm{O}$. The potassium iodate solution which was used throughout the entire investigation contained 3.5667 grams of $\mathrm{KIO}_{3}$ per liter, corresponding to 0.00400 gram of antimony for I cc.

The following results were obtained:

$\begin{array}{ccc}\begin{array}{c}\text { Sb taken. } \because \\ \text { Gram. }\end{array} & \mathrm{KIO}_{3} \text { used. } & \text { Sb found. } \\ 0.1000 & 24.85 & 0.0994 \\ 0.1000 & 24.90 & 0.0996 \\ 0.0490 & 12.20 & 0.0488\end{array}$

The following method of analysis for alloys has been worked out: Take 0.5 gram of alloy in the form of drillings or chips in a $200 \mathrm{cc}$. Erlenmeyer flask. Add Io cc. of concentrated sulphuric acid and heat until the alloy is entirely decomposed.3 Boil the solution gently for about 2 minutes after the lead sulphate has become white, allow the solution to cool to room temperature, dilute with i $5 \mathrm{cc}$. of cold water, allow to cool somewhat, add I5 cc. of I : I hydrochloric acid, shake thoroughly and filter off the lead sulphate on a Gooch crucible, washing with small quantities of the same hydrochloric acid. Transfer the filtrate to a glass stoppered bottle of about $250 \mathrm{cc}$. capacity, add $5 \mathrm{cc}$. chloroform, I $5 \mathrm{cc}$. of concentrated hydrochloric acid, 4 and $5 \mathrm{cc}$. of iodine monochloride solution. ${ }^{5}$ Shake the titration bottle, let it stand for about five minutes and then titrate the liberated iodine with standard potassium iodate solution $^{6}$ until the chloroform is just decolorized after thorough shaking, which should be repeated in about a minute to make sure of getting the true end point. To make a second titration most of the liquid may be poured off, leaving the chloroform ready for use.

It should be observed that, as Andrews' has shown,

1 Loc. cit.

2 If the alloy contains less than 2 per cent. of antimony, it is better to take 1 gram or more, while with alloys very rich in antimony 0.1 or 0.2 gram will suffice.

3 If the flask is covered with an inverted porcelain crucible cover, the dissolving and boiling may be carried out without the escape of any disagreeable quantities of fumes, so that the hood need not be used.

4 To allow for dilution with the standard solution.

- To prepare this solution, dissolve 10 grams of potassium iodide and 6.44 grams of potassium iodate in $75 \mathrm{cc}$. of water, add $75 \mathrm{cc}$. of concentrated hydrochloric acid, then add a globule of chloroform in a glass stoppered bottle, and adjust exactly to a faint iodine color by shaking and adding dilute potassium iodide or potassium iodate solution as the case may require.

6 If the volume of potassium iodate solution used is much over 15 cc., it is advisable to add more concentrated hydrochloric acid to keep the strength near the $1: 1$ point. 